\title{
Curtain has fallen on hopes of legal bioprospecting
}

\section{Local communities, too, could have benefited from better health care and conservation.}

Sir - Your News Feature "The curtain falls" (Nature 414, 685; 2001) about the termination of the International Cooperative Biodiversity Group (ICBG) in Chiapas, Mexico, was an excellent analysis of the complex issues that brought this innovative research and development project to an unfortunate end. However, there are three misinterpretations in the article which we, as members of the US Interagency Technical Advisory Group to the ICBGs, would like to correct.

First, you state that the aim of an ICBG is to find natural products for treating important diseases in the United States. This multifaceted programme, supported by several US government agencies, actually has the goal of identifying potential drugs to enhance the public health of both developing and developed countries, while promoting economic development and conservation of local biodiversity. Each ICBG is required to focus on disease areas of local importance as well as those of importance elsewhere.

The Chiapas ICBG was no exception, and planned to research potential treatments for diarrhoea, respiratory conditions, infectious diseases, contraception and other locally important health needs. Substantial effort and investment is made by all ICBGs to help local organizations develop sustainable economic uses of their natural resources, as well as models for sharing profits and other benefits that emerge from collaborative research efforts.

Second, referring to the innovative theatre used by the Chiapas ICBG for developing informed consent in Maya communities, your article's standfirst asked "But did the plays distract attention from the involvement of commercial interests?". This could give the mistaken impression that distracting the audience from the possibility of commercial development was intentional or desirable. The participation of private companies to develop and market therapeutic agents is detailed in every publication or presentation about the ICBG programme, and was an explicit component of this community theatre.

Finally, you state that the National Institutes of Health asked the Chiapas principal investigator, Brent Berlin, to suspend collecting plant material late last year. In fact, the ICBG never initiated collections for drug discovery. Pressed, fumigated botanical specimens for taxonomic museum reference were collected in the first year of the project under a scientific collection permit issued by the Mexican government. When that permit expired, the group suspended these collections. The investigators subsequently decided that it was unproductive to pursue federally permitted taxonomic collections because these had provoked concern among people who were confusing basic research for taxonomy with potentially commercial drug discovery.

The controversy that has led to the termination of the Chiapas ICBG may have a chilling effect on the ability of scientists to develop transparent and ethical collaborations in natural-products drug discovery, biotechnology and other sustainable uses of biodiversity for local and global benefit. In our opinion, all parties have lost, not least local communities in developing countries. These stand to benefit from improvements in health care and from enhanced capability to use and conserve their disappearing biological resources and associated traditional knowledge.

\section{Joshua Rosenthal}

Division of International Training and Research, Fogarty International Center, National Institutes of Health, 31 Center Drive, Bethesda, Maryland 20892, USA

Other signatories to this letter:

Flora Katz, Gordon Cragg, Yali Hallock, George Johnson, Linda Brady, Michael Gottlieb, Chris Tseng, Richard Hawks, Jamie Biswas National Institutes of Health, Bethesda, Maryland, USA Joann Roskoski, James Rodman, Elizabeth Lyons, Michael Willig National Science Foundation, Arlington, Virginia, USA

Carol Kramer-LeBlanc, Anne Bertinuson US Department of Agriculture, Washington DC, USA

\section{Don't fight fire with fire}

Sir - The fires that ringed Sydney in December and January were as intense as any in the past 70 years (see Nature 415, $105 ; 2002)$. Over half a million hectares of bush land burnt and more than 10 times this area threatened but saved; about 100 houses were destroyed. The fires have stimulated strident demands for more frequent and extensive burning off ('hazard reduction burning'), especially in national parks, to protect property.

Most authorities agree, though, that protection is not guaranteed by this approach. The way forward is not simple. It must include strategic (not broad-scale) hazard reduction, continued emphasis on fire-fighting, education and better town planning in areas of high fire risk.

The urban areas of Sydney and Wollongong are surrounded by large conservation areas: a World Heritage Area, several national parks and water catchments. The principal objective of the New South Wales National Parks \& Wildlife Service, the agency responsible for most of this land, is "to protect and conserve natural and cultural heritage", including natural ecosystems, biodiversity in general, and species and communities listed as vulnerable and endangered. Although the proximity of the threatened conservation areas to Sydney makes the city stunningly beautiful, the variegated boundaries create an unenviable challenge for land managers, who have to protect the native biota inside the boundaries from big fires while protecting people outside.

Many plant and animal species are threatened by too-frequent fires, even though they evolved with fire as a natural disturbance. Paradoxically, some plants most favoured by fire are actually killed by it. They re-emerge, phoenix-like, from seeds that were protected from heat in woody fruits or the soil. The juvenile period - the time needed for the new recruits to develop a seed bank of their own - can exceed 10 years for some species. A second fire during this time could spell local extinction. Also, animals requiring dense habitat are confined to areas that do not burn frequently. These species need long-unburnt refuges from which to reinvade, once the burnt vegetation recovers to an appropriate stage. Frequent burning sustains unsuitable habitat. The current state of knowledge is summarized in Flammable Australia: The Fire Regimes and Biodiversity of a Continent, edited by R. A. Bradstock, J. E. Williams and A. M. Gill (Cambridge University Press, 2001).

The primary conservation objective of the national parks is that of managing toofrequent fires, so managers and politicians must resist the demand for broad-scale hazard reduction. Perhaps neighbouring property and lives can be protected by attention to the boundaries of conservation areas, without burning frequently throughout the parks. This strategy has been pursued in New South Wales national parks, to the extent that biodiversity conservation in these boundary zones may be sacrificed to protect property. Backed by a well trained, resourced and coordinated fire-fighting effort, this strategy meant that remarkably few houses were lost in the recent fires. Now it is time to find and defend solutions that also protect the parks. Rob Whelan

Institute for Conservation Biology, University of Wollongong, Wollongong, NSW 2522, Australia 